\title{
Design of Anhydrous Electrorheological Suspensions Based on Phosphate Cellulose
}

\author{
Byeng-Gil AhN, Ung-Soo CHOI, and Oh-Kwan KwON \\ Tribology Research Center, Korea Institute of Science and Technology, \\ P.O. BOX 131, Cheongryang, Seoul 130-650, Korea
}

(Received August 31, 1998)

\begin{abstract}
The electrorheological (ER) behavior of suspensions in silicone oil of phosphate cellulose particles (average particle size : $17.77 \mu \mathrm{m}$ ) was investigated at room temperature with electric fields up to $2.5 \mathrm{kV} \mathrm{mm}^{-1}$. For development of anhydrous ER suspensions for use at wide temperature range, it was sought the effect of the phosphate-ester reaction of celluloses on ER activity. Current density and conductivity of anhydrous ER suspensions of phosphate cellulose particles could be controlled by varying phosphoric acid concentration in phosphate-ester reactions of cellulose. When cellulose particles were treated by the phosphoric acid between $2.5 \mathrm{M}$ and $3.0 \mathrm{M}$, ER suspensions containing phosphate cellulose particle electrorheological effect $\left(\tau_{\mathbf{A}} / \tau_{0}\right)$ was greatest.

KEY WORDS Anhydrous Electrorheological Suspension / Phosphate-Ester Reaction of Cellulose

Electrorheological Effect $\left(\tau_{\mathbf{A}} / \tau_{0}\right)$ / Dielectric Constant / Current Density / Electrical Conductivity /
\end{abstract}

The influence of electric fields on the deformation and flow properties of materials has been of interest for many years. Recently, there has been renewed interest in a particular branch of these electric field effects: the electrorheological effect (ER effect). The ER effect is sometimes called the Winslow effect, after Willis Winslow who described it first. ${ }^{1}$ Winslow found that strong electric field application to nonaqueous silica suspensions activated with a small amount of water caused rapid solidification of the originally fluid material.

Rheological parameters which describe ER transition are dynamic yield stress and steady shear viscosity. Till quite recently, electrorheological fluids have been modeled as Bingham plastics. ${ }^{2-4}$ This means that flow is observed only after exceeding a minimum yield stress. The equation for a Bingham body is

$$
\tau=\tau_{\mathrm{y}}+\eta_{\mathrm{pl}} \cdot \dot{\gamma}
$$

Where $\tau_{\mathrm{y}}$ is dynamic yield stress, $\eta_{\mathrm{pl}}$ plastic viscosity, and $\dot{\gamma}$ shear rate. Application of an electric field to ER fluid, dynamic yield stress increases dramatically while plastic viscosity remains essentially unchanged. Useful characteristics of ER suspensions which show Bingham plastics are dynamic yield stress dependent upon intensity of an electric field, whose variation range is large, stepless and reversible, and response time is very fast (approximately $1 \mathrm{~ms}) .^{5}$

Generally, ER suspensions which show electrorheological effect may be divided as wet-based and dry-based ER suspensions. In wet-based ER suspensions, water is a required dopant to activate the suspension. The role of water in the ER effect has remained unidentified as well as the difficulty in practical device design. One primary disadvantage of wet-based ER suspensions is the limited temperature range of usage. Presumably, viscous and conductive heating of the fluid causes the eventual loss of water result in loss of ER activity on the electric fields. ${ }^{6}$ The presence of water leads to dielectric breakdown, corrosion and high power consumption for ER systems with substantial quantity of water. $^{7}$ Recently, aluminosilicate ${ }^{8}$ and poly(acene quinones $)^{9}$ were proposed as particulates to be used in dry-based ER fluids. In dry-based ER suspensions, the mechanisms of "water bridging" between particles and interaction of electric double layers are not possible; the most probable mechanism would be stringing of the polarized particles. While the conductivity of aluminosilicate was not reported exactly, the current densities of the ER suspensions seem comparable to those of the wet-based ER suspensions. ER suspensions made from poly(acene quinones) exhibit high current densities. ${ }^{10,11}$ The bulk conductivities of the poly(acene quinones) ranged from $10^{-4}$ to $10^{-9} \Omega^{-1} \mathrm{~cm}^{-1}$. A high dielectric constant usually carries with it a finite conductivity, and this leads to high current in the fibrillated ER suspension. For application of ER suspension on high temperature range (approximately $80^{\circ} \mathrm{C}$ ), high conductivity is a major problem. While maintaining the ER effect on electric fields, "how the conductivity and dielectric constant of the ER suspension can be controlled ?" are important questions.

For development of anhydrous ER suspensions with high ER effect on electric fields, a dry-based ER suspension with phosphate cellulose particles dispersed in silicone oil $(50 \mathrm{cS})$ was designed. To understand the roles of conductivity and dielectric constant in ER suspensions, shear stress-strain rate behavior was measured along with electrical properties as a function of phosphate-ester reaction of cellulose. To control the electrical conductivity and increase ER effect of anhydrous ER suspensions, conductivity and ER effect on the variation in phosphoric acid concentration at phosphate-ester reaction ${ }^{12}$ were studied.

Electrical conductivity and ER effect of anhydrous ER suspensions based on phosphate cellulose could be controlled by varying phosphoric acid concentration at phosphate-ester reaction of cellulose.

\section{EXPERIMENTAL}

\section{Design of Anhydrous ER Suspensions}

Synthesis of Phosphate Cellulose Particles. Water solutions at several concentrations of phosphoric acid (85\% orthophosphoric acid) containing $4 \mathrm{M}$ of urea were 


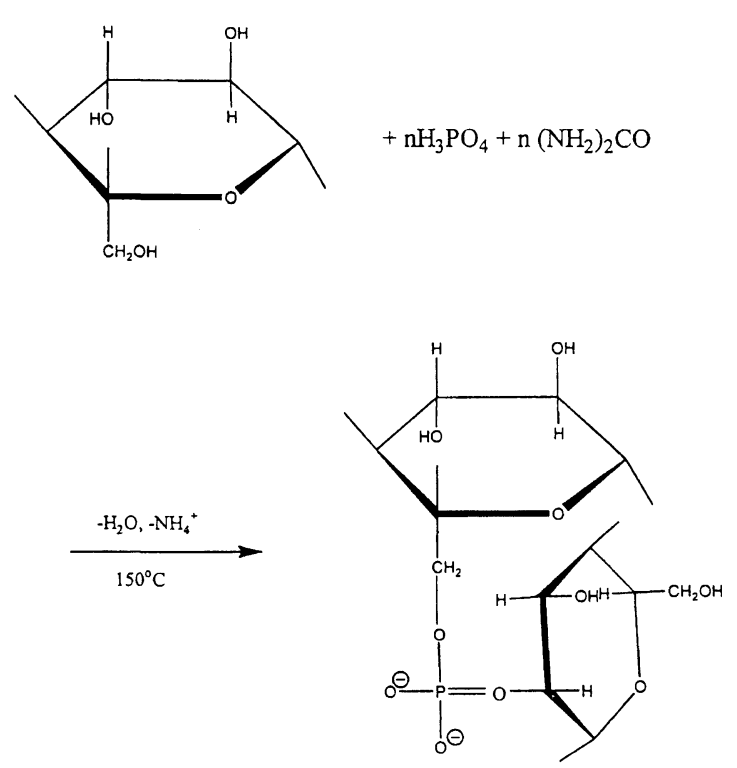

Figure 1. Phosphoric ester reactions of cellulose.

made. Each system was stirred for half an hour at room temperature for uniformity of solution, and ammonium phosphate was generated by reaction of phosphoric acid and urea. Raw cellulose particles (Sigmacell, Sigma Chemical Co., average particle size $20 \mu \mathrm{m}$ ) were introduced into the ammonium phosphate solution and maintained at $20^{\circ} \mathrm{C}$ for $24 \mathrm{~h}$. After $24 \mathrm{~h}$, the cellulose particles were separated from the ammonium phosphate solution by filtering and placed in an electrical furnace for phosphate-ester reaction of cellulose particles. After maintaining $2 \mathrm{~h}$ at $80^{\circ} \mathrm{C}$, the furnace temperature was increased to $150^{\circ} \mathrm{C}$ and maintained for $2 \mathrm{~h}$ as seen in Figure 1. The phosphate cellulose particles made from phosphate-ester reaction of cellulose were neutralized by 5-6 washings with distilled water. Particle size of phosphate cellulose particles was controlled by sieve shaker (passing $26 \mu \mathrm{m}$ sieve). To remove moisture from the particles, they were dried in the vacuum drying at $100^{\circ} \mathrm{C}$ oven for $48 \mathrm{~h}$. Particle size distribution measured by Image Analyzer System (Model Omnimet 2, UK) is presented in Figure 2, and mean particle size was $17.77 \mu \mathrm{m}$.

Preparation of Phosphate Cellulose ER Suspensions. Dried phosphate cellulose particles were mixed with anhydrous silicone oil $(50 \mathrm{cS}$, Shin-Etsu Silicone Co., Japan), prepared by exposing oil to molecular sieves for one week. ER suspensions were made by mixing $20 \mathrm{vol} \%$ of phosphate cellulose particles and $80 \mathrm{vol} \%$ of silicone oil with the ball-mill for $24 \mathrm{~h}$ for uniform dispersion of the fine particles into the oil.

\section{Characterization of ER Suspensions}

Electrical Measurement. Dielectric and conductive properties of the phosphate cellulose ER suspensions were measured with variation in phosphoric acid concentration at phosphate-ester reaction of cellulose. The arrangement of dispersed particles (i.e., chain formation) influences the electrical properties of the fluids (Miller and Jones, 1988), ${ }^{13}$ and thus the following method was used to obtain dielectric properties of ER suspensions and the experiment was performed at $20^{\circ} \mathrm{C}$

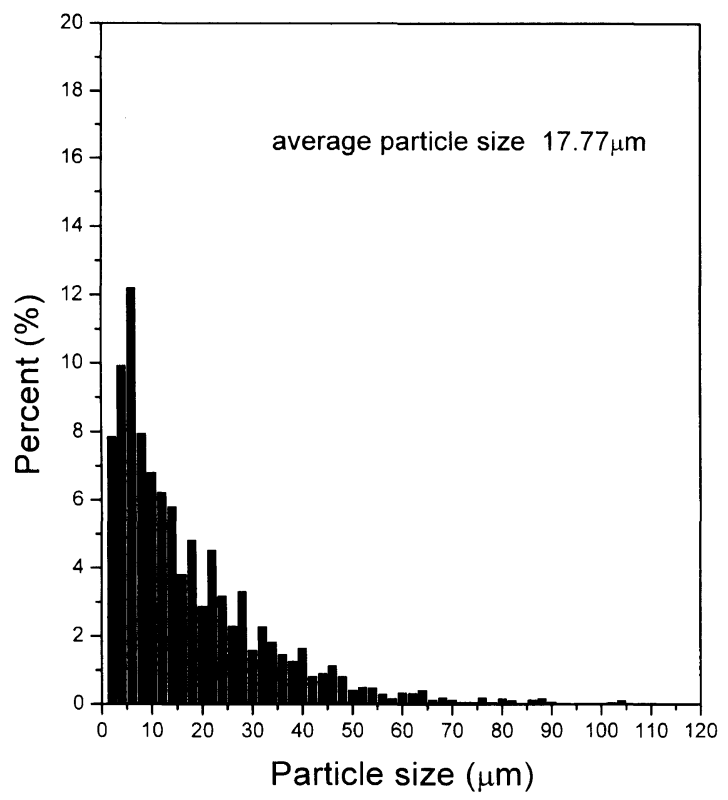

Figure 2. Number distribution of particle size of phosphate cellulose.

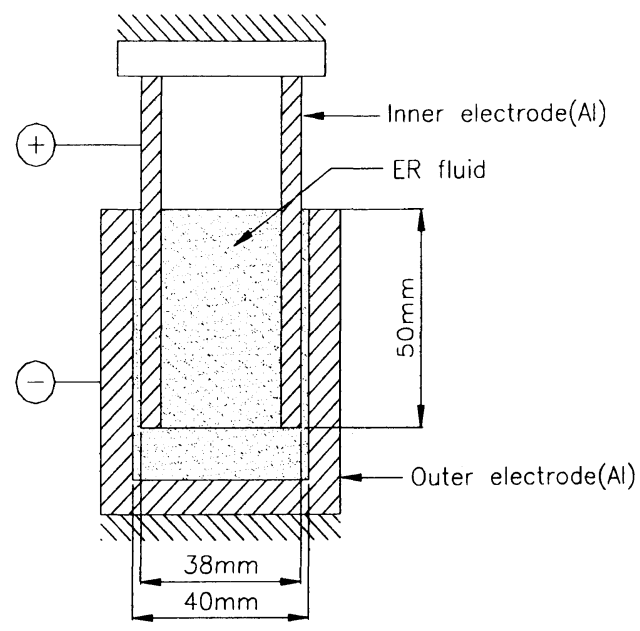

Figure 3. Schematic diagram of the electrode for measuring current density and electrical conductivity of ER fluids.

on a DC bias LCR meter (Hewlett Packard, HP 4263B, U.S.A.). Dielectric constants were calculated by capacitance $^{14}$ of ER fluids. An LCR meter was used with high voltage bias. The equation used was as follows,

$$
K_{\mathrm{s}}=\left[C_{\text {measure }}-C_{\text {air }}\right] /\left[C_{\text {theory }}+1\right]
$$

where $K_{\mathrm{s}}$ is the dielectric constant of ER fluids, $C_{\text {measure }}$ measuring capacitance of ER fluids, $C_{\text {air }}$ capacitance of air, and $C_{\text {theory }}$ theoretical capacitance of free space which can calculate as,

$$
C_{\text {theory }}=2 \pi \varepsilon_{0} L / \ln \left(r_{2} / r_{1}\right)
$$

where $\varepsilon_{0}$ is the dielectric constant of free space, $L$ cylinder gab between bob and cup, and $r_{2}, r_{1}$ inner radius of cup and outer radius of bob, respectively, in Figure 3. DC conductivity determined by measuring the current on the high electric field conditions. Fluid specimens were held in an aluminum cup as seen in Figure 3, whose outer diameter, inner diameter and height were $40 \mathrm{~mm}, 38 \mathrm{~mm}$ and $50 \mathrm{~mm}$, respectively, with a flat bottom made by plastic. The electrode area for calculating electrical 


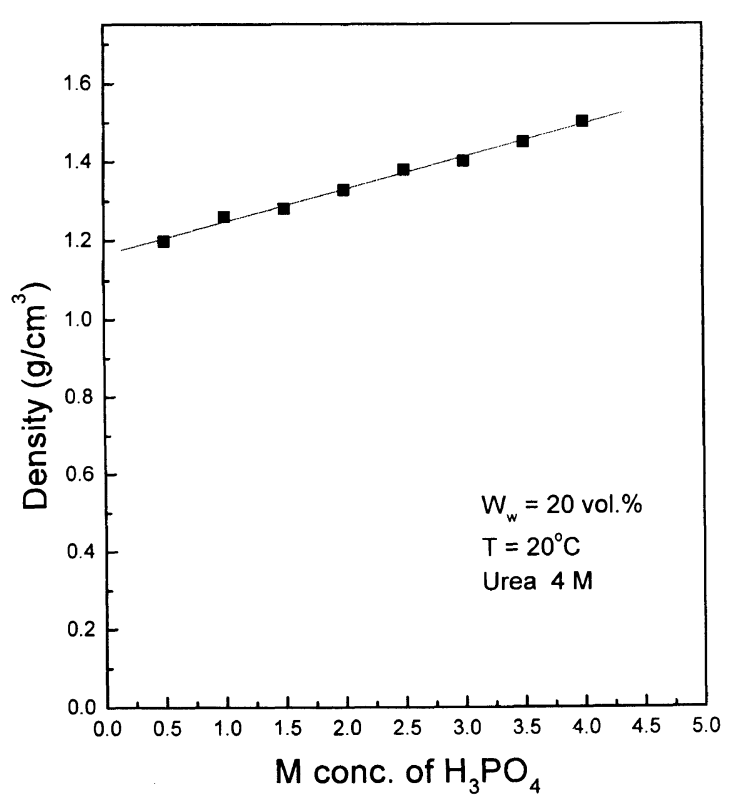

Figure 4. Density of phosphate cellulose particles in $\mathrm{M}_{\text {concn }} \mathrm{H}_{3} \mathrm{PO}_{4}$.

properties was $59.69 \mathrm{~cm}^{2}$ and thickness, $1 \mathrm{~mm}$. When I used other polymer particles, poly ( $p$-phenylene), as ER particles, the particles aggregated to one electrode under DC fields. But the developed ER particles, phosphate cellulose, did not aggregate to one electrode under high DC fields $\left(5 \mathrm{kV} \mathrm{mm}^{-1}\right)$. Data were collected after the ER suspension was initially stirred at $E=0$, and immediately check up to $4.5 \mathrm{kV} \mathrm{mm}^{-1}$. The equation of current density $\left(j_{\mathrm{f}}\right)$ is

$$
j_{\mathrm{f}}=\frac{I_{\mathrm{f}}}{A}
$$

The conductivity $\left(\sigma_{\mathrm{f}}\right)$ of ER suspensions was calculated as,

$$
\sigma_{\mathrm{f}}=\frac{\Delta j_{\mathrm{f}}}{\Delta E}
$$

where $A$ is electrode area in contact with ER suspension, $I_{\mathrm{f}}$ current under constant electric field, $E$ DC electric field and $\Delta j_{\mathrm{f}}$ the difference of current density of ER suspension as the difference in electric field $(\Delta E)$.

Rheological Measurement. Shear stress-strain rate data for ER suspensions were determined using viscometer, a coaxial arranged design for relatively low strain and strain rate used by a conventional mechanical test machine. High voltage was supplied with a Keithley High Voltage Supplier (Model 248, U.S.A.) connected to the cup and bob of Couette type viscometer by a thin wire. Data were obtained for strain rate up to $110 \mathrm{~s}^{-1}$ at $20^{\circ} \mathrm{C}$. The rheological behavior of the phosphate cellulose ER suspensions was measured with variation in phosphoric acid concentration at phosphate-ester reaction of cellulose. For ER suspensions, the electrorheological effect (ER effect, $\eta_{\mathrm{R}}$ or $\tau_{\mathrm{R}}, \eta_{\mathrm{R}}=\eta_{\mathrm{A}} / \eta_{0}$ or $\left.\tau_{R}=\tau_{A} / \tau_{0}\right)$ is very important for application of real mechanical parts, where $\eta_{\mathrm{A}}$ (or $\tau_{\mathrm{A}}$ ) and $\eta_{0}$ (or $\tau_{0}$ ) stand for the apparent viscosity (or shear stress) with and without an electric field, respectively.

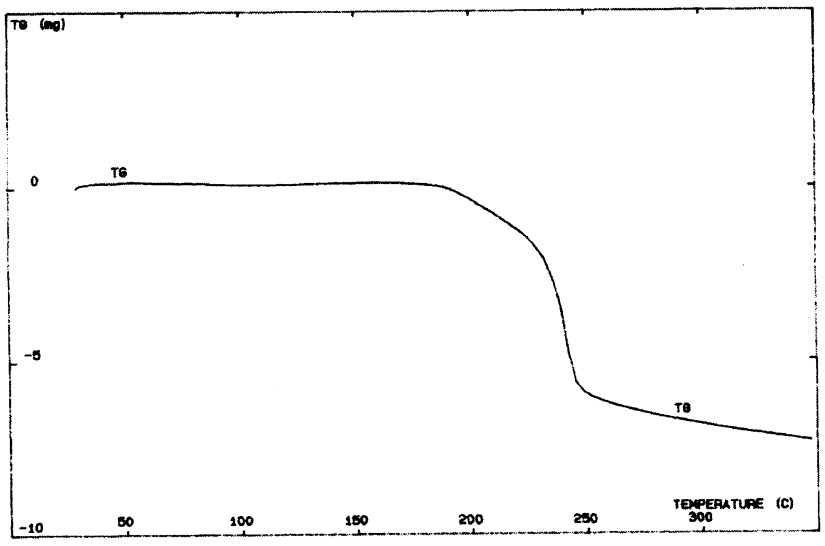

(a) TGA

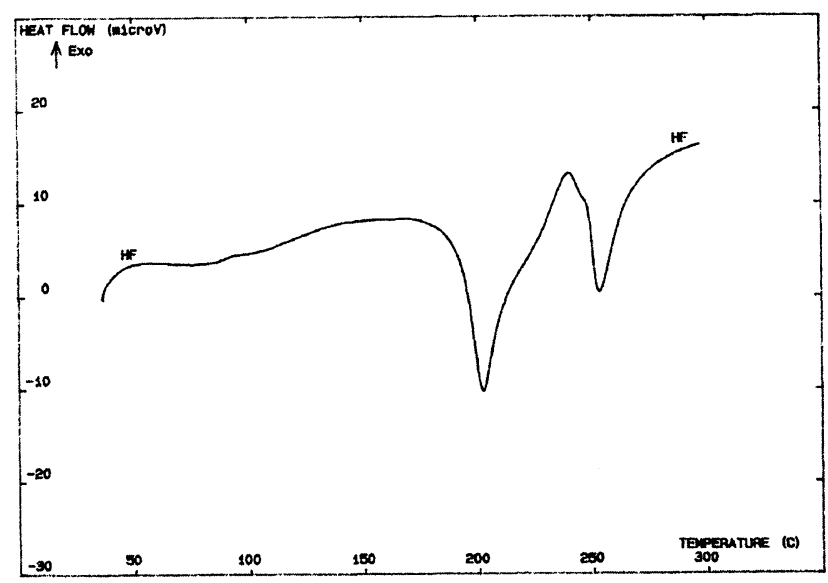

(b) DTA

Figure 5. TGA (a) and DTA (b) curves of phosphate cellulose particles treated with $2.5 \mathrm{M}$ phosphoric acid and $4 \mathrm{M}$ urea.

\section{RESULTS AND DISCUSSION}

\section{Phosphate Cellulose Particles}

Density of phosphate cellulose particles was measured by Pycnometer at $1.2 \pm 0.05 \mathrm{~g} \mathrm{~cm}^{-3}$ to $1.5 \pm 0.05 \mathrm{~g} \mathrm{~cm}^{-3}$ and is shown in Figure 4. The density of phosphate cellulose particles linearly increased with phosphoric acid concentration in phosphate-ester reaction of cellulose, since decrease of phosphate particle mass was generated with rise of phosphoric acid concentration.

The thermal stability of phosphate cellulose particles approached $200^{\circ} \mathrm{C}$ from TG-DTA curve, as shown in Figure 5. In case of phosphate cellulose particles, no chemical reaction or decreasing weight was found below $200^{\circ} \mathrm{C}$. The decomposition temperature of cellulose was between $200^{\circ} \mathrm{C}$ and $270^{\circ} \mathrm{C} .{ }^{15}$ Thus it could be estimated that the phosphate cellulose particles dispersed into silicone oil were stable below $200^{\circ} \mathrm{C}$, which proved that the ER suspensions based on phosphate cellulose were anhydrous ER suspensions.

The IR spectra of the phosphate cellulose particles, as shown in Figure 6 (a), displayed a peaks $\left(1400 \mathrm{~cm}^{-1}\right)$ corresponding to the appearance of phosphate-ester reaction. ${ }^{16}$ Figure $6(\mathrm{~b})$ shows the correlation between phosphoric acid concentration and phosphorus (P) content in phosphate cellulose particles. The phosphorus (P) content in phosphate cellulose particles was proportional to phosphoric acid concentration as seen 


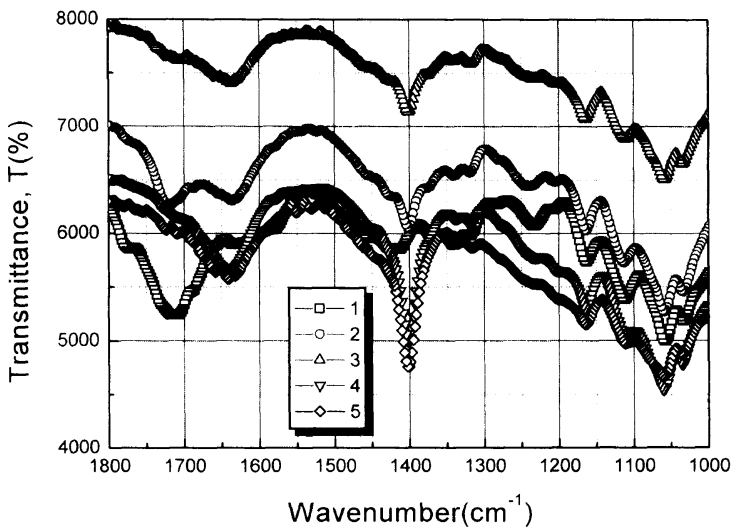

(a)

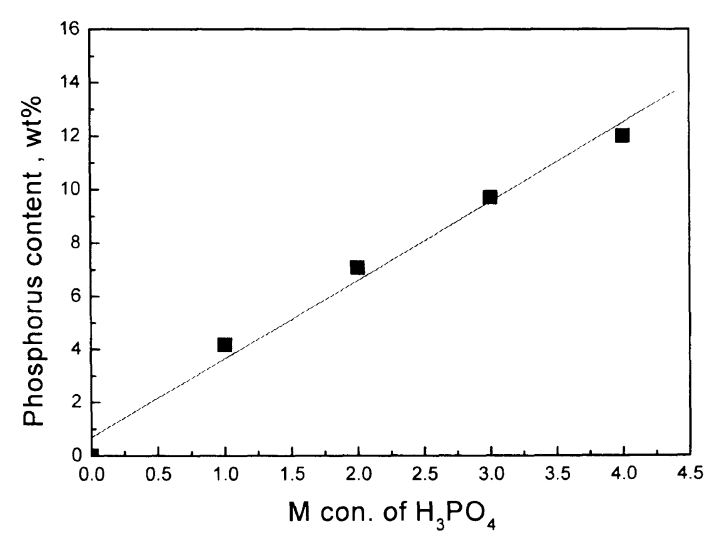

(b)

Figure 6. Infrared spectrum and phosphorus content of phosphate cellulose. (a) Infrared spectrum: 1, 0 M; 2, 1 M; 3, 2M; 4, 3M; 5, 4 M of $\mathrm{H}_{3} \mathrm{PO}_{4}$. (b) Phosphorus content vs. $\mathrm{M}$ concn $\mathrm{H}_{3} \mathrm{PO}_{4}$.

in Figure 6 (b).

\section{Electrical Properties of ER Suspensions}

The continuous phase of on an ER suspension is typically a nonconductive and low dielectric constant oil. The current density and conductivity of phosphate cellulose ER suspensions, as shown in Figures 7 and 8, were measured at room temperature. Although the volume fraction of phosphate particles was maintained constantly, current density and conductivity of ER suspensions were measured differently as seen in Figures 7 and 8 . Current density increased with phosphoric acid concentration at phosphate-ester reaction of cellulose, and was proportional to the electric field with power law under constant concentration $\left(j_{\mathrm{f}} \propto E^{\mathrm{m}}, m=1.99-2.38\right)$.

As seen in conductivity measurement in Figure 8, increase in phosphoric acid concentration $\left(M_{\mathrm{p}}\right)$ resulted in exponential increase in conductivity under a constant electric field $\left(\sigma_{\mathrm{f}} \propto M_{\mathrm{p}}^{4.238}\right)$.

Therefore, the conductivity of anhydrous ER suspensions based on phosphate cellulose could be controlled with phosphoric acid concentration of phosphate-ester reaction of cellulose, and it was possible to make optimum ER suspensions.

Under the assumption that the volume fraction $(\phi)$ is small and absolute temperature $(T)$, radius of colloidal particles $(R)$ and electric charge of insulation oil $\left(e_{0}\right)$ are constant, increment of the dielectric constant $(\Delta \varepsilon)$ of ER

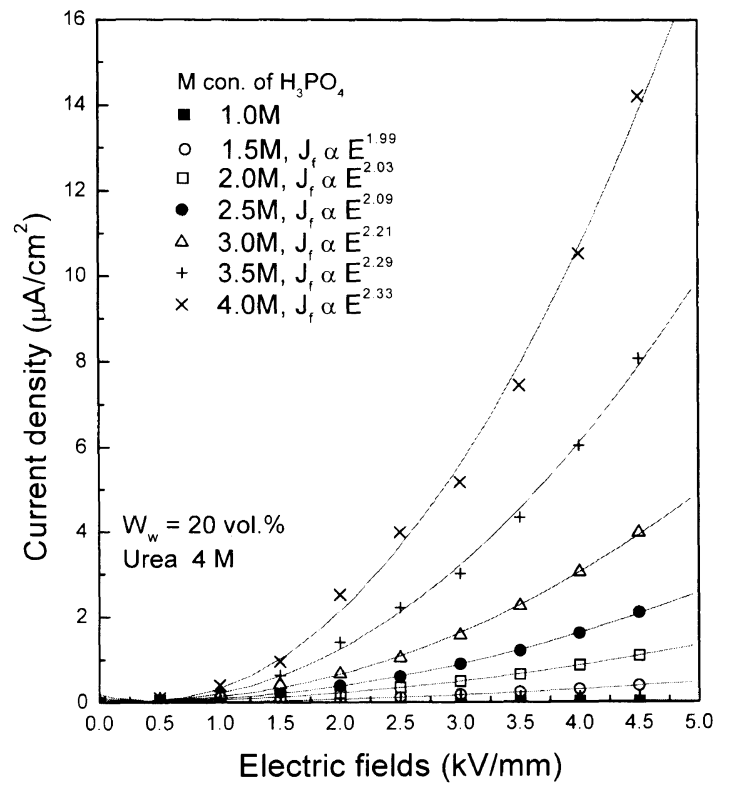

Figure 7. Current density as a function of electric fields for phosphate cellulose ER fluids at room temperature.
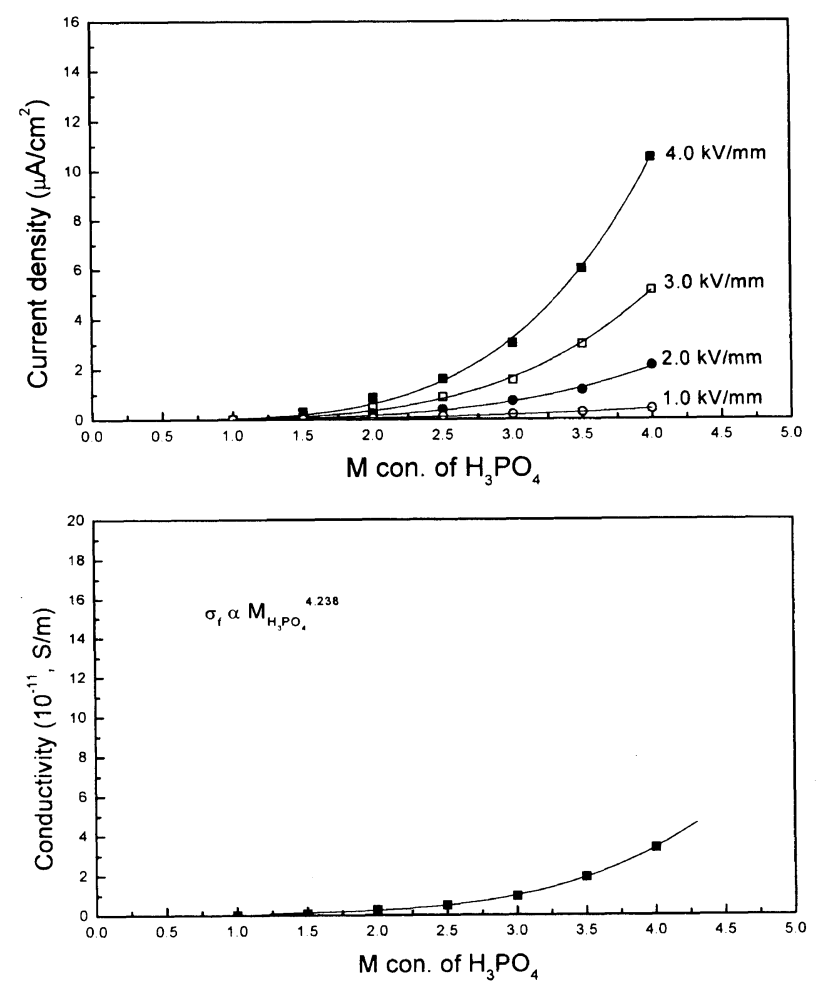

Figure 8. Current density and conductivity of phosphate cellulose ER fluids for $\mathrm{M}$ concn $\mathrm{H}_{3} \mathrm{PO}_{4}$ at room temperature.

suspensions was found proportional to the product of volume fraction $(\phi)$ and surface charge density $\left(\sigma_{0}\right)$ in colloidal spherical particles. ${ }^{17}$

$$
\Delta \varepsilon \propto \phi \cdot \sigma_{0}
$$

The dielectric behavior of phosphate cellulose ER suspensions (constant volume fraction) is shown in Figure 9. The dielectric constant of ER suspensions based on phosphate cellulose particles was proportional to phosphoric acid concentration (in case of below $2 \mathrm{M}$ concentration) of phosphate-ester reaction when $\phi$ and $R$ were constant as seen in Figure 9. The dielectric 


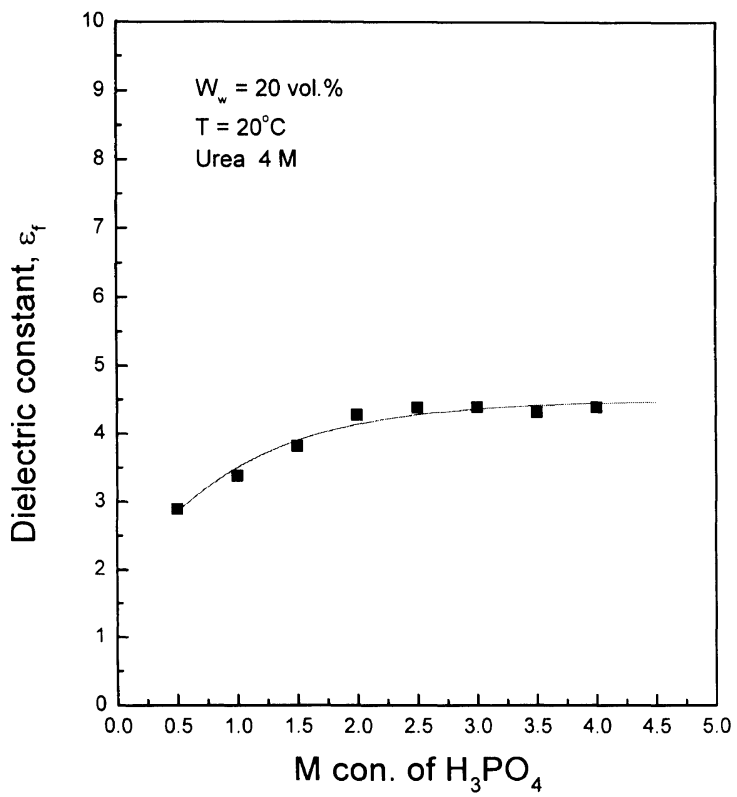

Figure 9. Dielectric constant behavior of phosphate cellulose ER fluids at $\mathrm{M}$ concn $\mathrm{H}_{3} \mathrm{PO}_{4}$.

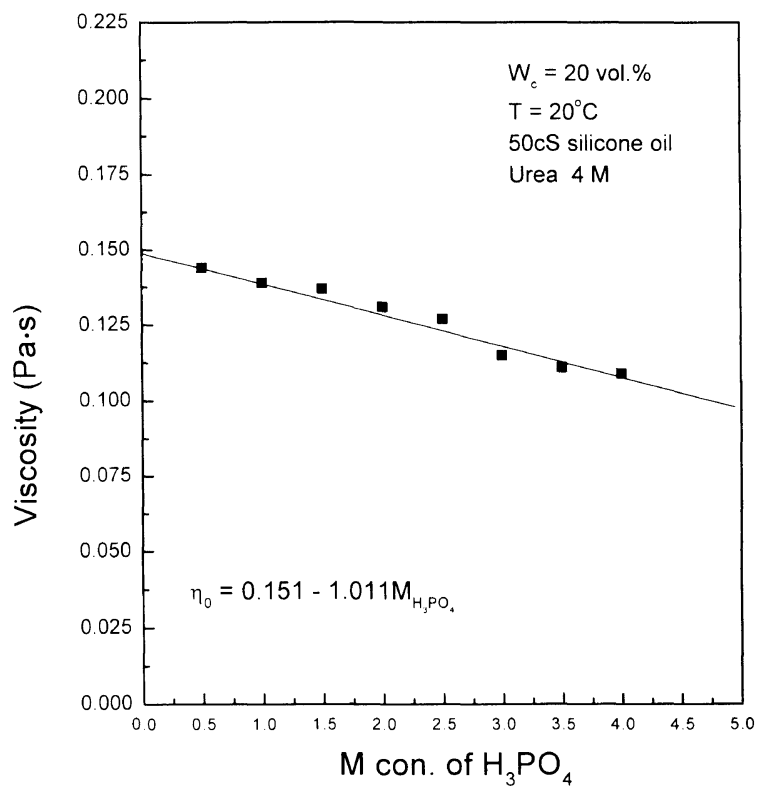

Figure 10. Viscosity of phosphate cellulose ER fluids at M concn of $\mathrm{H}_{3} \mathrm{PO}_{4}$ without electric fields.

constant was maintained constant when higher than 2 M. Equation 5 may thus be changed as,

$\Delta \varepsilon \propto \phi \cdot M_{\mathrm{p}},\left(M_{\mathrm{p}} \leq 2, M_{\mathrm{p}}:\right.$ phosphoric acid concentration $)$

Therefore, the phosphoric acid concentration $\left(M_{\mathrm{p}}\right)$ is closely related to the surface charge density $\left(\sigma_{0}\right)$ of phosphate cellulose particles.

\section{Rheological Properties of ER Suspensions}

The viscosity $\left(\eta_{0}\right)$ without electric field has large influence on the ER effect $\left(\eta_{\mathrm{R}}=\eta_{\mathrm{A}} / \eta_{0}\right.$ or $\left.\tau_{\mathrm{R}}=\tau_{\mathrm{A}} / \tau_{0}\right)$ as seen in Figure 10. The viscosity behavior of developed ER fluids was noted for Newtonian fluids under without DC fields. When the volume fraction of phosphate cellulose particles was maintained constant, $\eta_{0}$ decreased

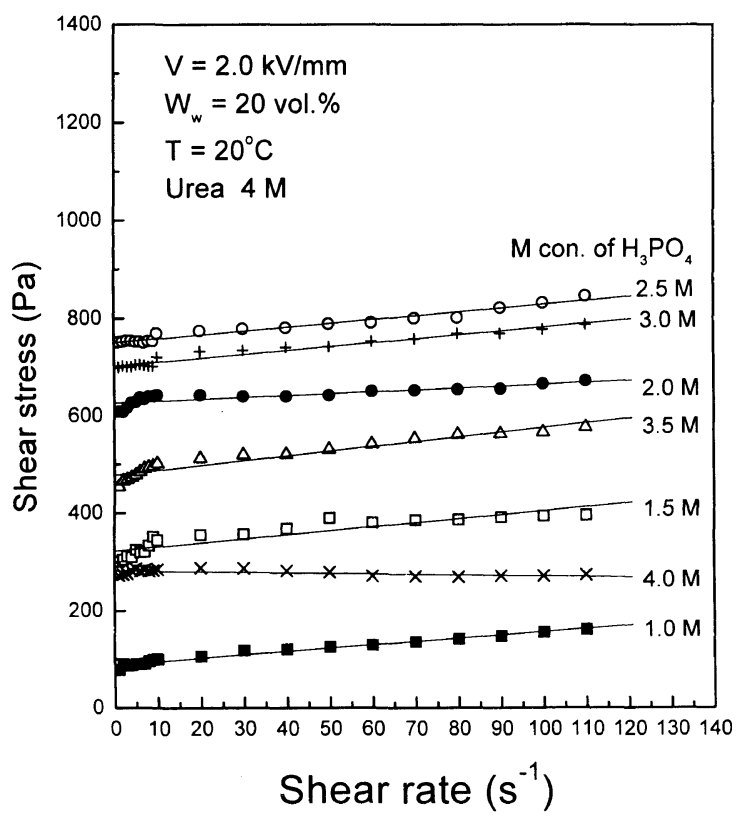

Figure 11. Shear stress $v s$. shear rate for phosphate cellulose ER fluids at $2.0 \mathrm{kV} \mathrm{min}^{-1}$.

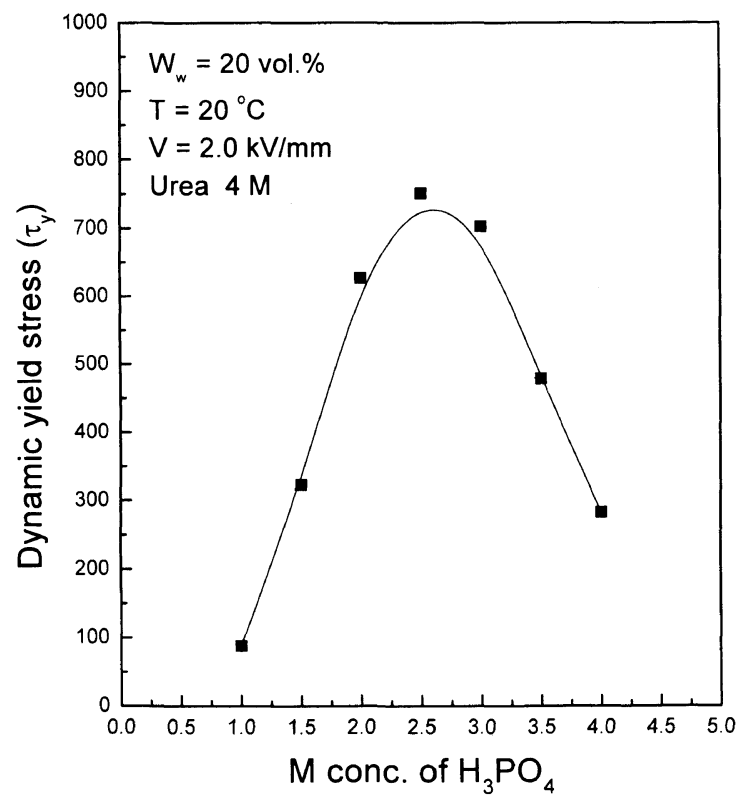

Figure 12. Dynamic yield stress of phosphate cellulose ER fluids on $\mathrm{M}$ concn $\mathrm{H}_{3} \mathrm{PO}_{4}$.

with increase of phosphoric acid concentration $\left(M_{\mathrm{p}}\right)$ in phosphate-ester reaction of cellulose. Therefore, the relations between $\eta_{0}$ and $M_{\mathrm{p}}$ is as follows.

$$
\begin{aligned}
& \eta_{0}=0.151-1.011 \times M_{\mathrm{p}}, \\
& \quad\left(M_{\mathrm{p}}:\right. \text { phosphoric acid concentration) }
\end{aligned}
$$

Shear stress-strain rate behavior of anhydrous ER suspension based on phosphate cellulose was measured with a Couette type viscometer at constant electric field, $2.0 \mathrm{kV} \mathrm{mm}^{-1}$, as shown in Figure 11 . The relationship between the dynamic yield stress $\left(\tau_{\mathrm{y}}\right)$ calculated from the Figure 11 and phosphoric acid concentration $\left(M_{\mathrm{p}}\right)$ is illustrated in Figure 12.

From Figures 11 and 12, ER suspensions based on phosphate cellulose exhibit Bingham behavior under 


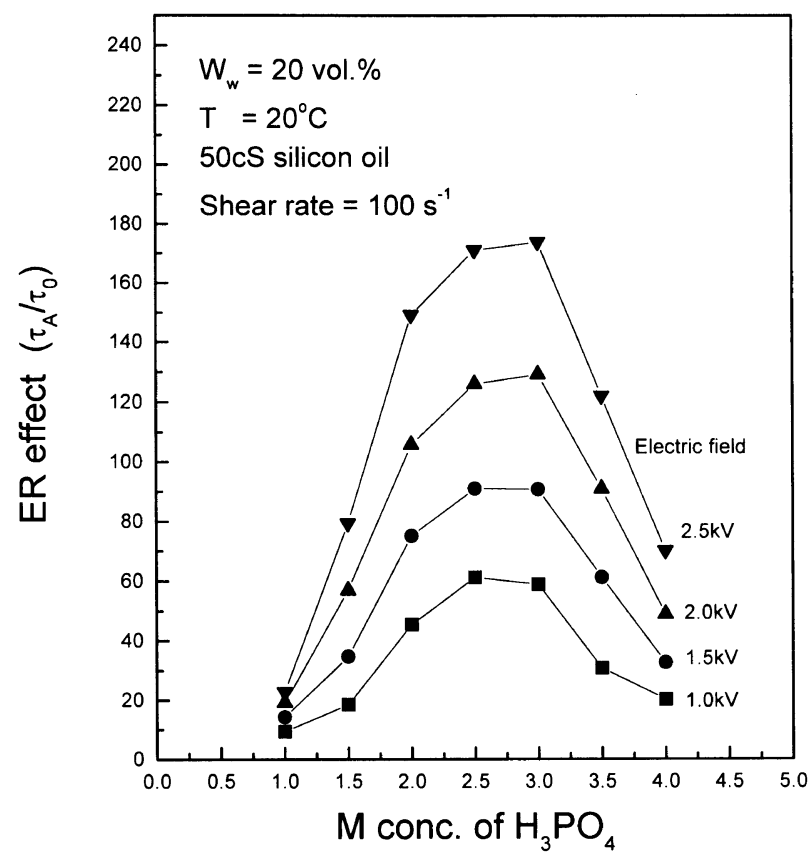

Figure 13. Electrorheological effect of phosphate cellulose ER fluids on $\mathrm{M}$ concn $\mathrm{H}_{3} \mathrm{PO}_{4}$.

electric field. When the phosphoric acid concentration was $2.5 \mathrm{M}$, the highest shear stress $(\tau)$ and dynamic yield stress $\left(\tau_{\mathrm{y}}\right)$ were measured. When cellulose particles were treated by phosphoric acid of $2 \mathrm{M}$, anhydrous ER suspensions based on phosphate cellulose developed in this study showed the highest dielectric constant, which remained nearly constant above $2 \mathrm{M}$ as seen in Figure 9. However, current density and conductivity increased with power law on rising phosphoric acid concentration $\left(M_{\mathrm{p}}\right)$ as seen in Figures 7 and 8. Therefore, shear stress should decrease due to increase in current density and conductivity. Generally, when current density of ER suspensions is over $20 \mu \mathrm{A} \mathrm{cm}^{-2}$ at $4.5 \mathrm{kV} \mathrm{mm}^{-1}$, ohmic behavior can generate between electrodes. When ohmic behavior is measured, it is possible to decrease of electric field between electrodes. ${ }^{18}$

From the results of Figures 11 and 12, the ER effect $\left(\tau_{\mathrm{A}} / \tau_{0}\right.$, at constant shear rate and electric field) of anhydrous ER suspensions based on phosphate cellulose on the phosphoric acid concentration is shown in Figure 13. When cellulose particles were treated with phosphoric acid at $2.5 \mathrm{M}$ to $3.0 \mathrm{M}$, the anhydrous ER suspensions showed the highest electrorheological effect $\left(\tau_{\mathrm{A}} / \tau_{0}\right)$.

\section{CONCLUSIONS}

ER suspensions based on phosphate cellulose showed anhydrous ER fluids. Current density and conductivity of anhydrous ER suspensions based on phosphate cellulose could be controlled with phosphoric acid concentration of phosphate-ester reaction of cellulose, and it was possible to make optimum ER suspensions using temperature conditions. The suspensions based on phosphate cellulose showed very strong ER effect. When the cellulose particles were treated by phosphoric acid between $2.5 \mathrm{M}$ and $3.0 \mathrm{M}$ in phosphate-ester reactions of cellulose, ER effect $\left(\tau_{\mathbf{A}} / \tau_{0}\right)$ was greatest. ER performance of anhydrous ER suspensions containing these phosphate cellulose particles was closely related to phosphoric acid concentration $\left(M_{\mathrm{p}}\right)$.

\section{REFERENCES}

1. W. M. Winslow, J. of Physics, 20, 1137, (1949).

2. T. B. Jones, "Orientation of Particle Chains in AC Electric Fields," Proceedings of Second International Conference on ER Fluid, 1990, pp $14-25$.

3. T. Miyamoto and M. Ota, "Theoretical and Experimental Study on ERF's Yield Stress," Part B, Vol. 59, No. 562, The Japan Society of Mechanical Engineers, 1993, pp 1822-1828.

4. N. Felici, J. N. Foulc, and P. Atten, "A Conduction Model of Electrorheological Effect," Proceedings of the Fourth International Conference on ER Fluid, July 20 - 23, 1993, pp 139-152.

5. C. Wei and A. Wei, "The Research in the Applications of ER Technology in Engineering," Proceedings of the International Conference Electrorheological Fluids, Oct. 1991, pp 465-469.

6. F. Deinega Yu and G. V. Vinogradov, "Electric Fields in the Rheology of Disperse Systems," Vol. 23, Rheo. Acta, 1984, pp $636-651$

7. T. C. Jordan and T. M. Shaw, "Electrorheology," Vol. 24, No. 5, IEEE Transactions on Electrical Insulation, Oct., 1989.

8. F. E. Filisko and L. H. Radzilowski, J. Rheol., 34, 539 (1990).

9. H. Block and J. P. Kelly, U.S. Patent 4687589, 1987.

10. H. A. Pohl and E. H. Engelhart, J. Phys. Chem., 66, 2085 (1962).

11. H. A. Pohl, and D. A. Opp, J. Phys. Chem., 66, 2121 (1962).

12. I. N. Ermolenko, I. P. Lyubliner, and N. V. Gulko, "Chemically Modified Carbon Fibers," VCH Publishers, New York, N.Y., 1990, pp 129-134.

13. H. Conrad, A. F. Sprecher, Y. Choi, and Y. Chen, J. Rheol., 35, 1393 (1991)

14. C. Wu and H. Conrad, J. Phys. D: Appl., 29, 3147 (1996).

15. J. Brandrup and E. H. Immergut, "Polymer Handbook," 3rd ed, John Wiley \& Sons, Inc. New York, N.Y., 1989, p V/122.

16. R. M. Silverstein, G. B. Clayton, and C. M. Terence, "Spectrometric Identification of Organic Compound," 5th ed, John Wiley \& Sons, Inc., New York, N.Y., 1989, p 164.

17. G. Schwarz, J. Phys. Chem., 66, 2636 (1962).

18. B.-G. Ahn, U.-S. Choi, O.-K. Kwon, and T.-J. Moon, J. KSTLE, 13, 115 (1997). 